\title{
Patency of the anterior choroidal artery covered with a flow-diverter stent
}

\author{
Hiroaki Neki, MD, Jildaz Caroff, MD, Pakrit Jittapiromsak, MD, Nidhal Benachour, MD, \\ Cristian Mihalea, MD, Leon Ikka, MD, Jacques Moret, MD, and Laurent Spelle, MD, PhD \\ Interventional Neuroradiology NEURI Center, Beaujon Hospital, Paris Diderot University, Clichy, France
}

OBJECT The concept of the flow-diverter stent (FDS) is to induce aneurysmal thrombosis while preserving the patency of the parent vessel and any covered branches. In some circumstances, it is impossible to avoid dangerously covering small branches, such as the anterior choroidal artery (AChA), with the stent. In this paper, the authors describe the clinical and angiographic effects of covering the AChA with an FDS.

METHODS Between April 2011 and July 2013, 92 patients with intracranial aneurysms were treated with the use of FDSs in the authors' institution. For 20 consecutive patients (21.7\%) retrospectively included in this study, this involved the unavoidable covering of the AChA with a single FDS during endovascular therapy. AChAs feeding the choroid plexus were classified as the long-course group (14 cases), and those not feeding the choroid plexus were classified as the short-course group (6 cases). Clinical symptoms and the angiographic aspect of the AChA were evaluated immediately after stent delivery and during follow-up. Neurological examinations were performed to rule out hemiparesis, hemihypesthesia, hemianopsia, and other cortical signs.

RESULTS FDS placement had no immediate effect on AChA blood flow. Data were obtained from 1-month clinical follow-up in all patients and from midterm angiographic follow-up in 17 patients (85.0\%), with a mean length of $9.8 \pm 5.4$ months. No patient in either group complained of transient or permanent symptoms related to an AChA occlusion. In all cases, the AChA remained patent without any flow changes.

CONCLUSIONS The results of this study suggest that when impossible to avoid, the AChA may be safely covered with a single FDS during intracranial aneurysm treatment, irrespective of anatomy and anastomoses.

http://thejns.org/doi/abs/10.3171/2014.11.JNS141603

KEY WORDS anterior choroidal artery; flow-diverter stent; aneurysm; vascular disorders

$\mathrm{U}$ SE of flow-diverter stents (FDSs) in the treatment of intracranial aneurysms is gradually increasing. FDSs have been shown to induce intraaneurysmal thrombosis by disrupting blood flow near the aneurysm neck, while preserving the patency of the parent vessel and covered branches. ${ }^{28}$ Although the thromboembolic complication rate is low, 1,10,28,37 studies on the effects of FDS placement on small branch vessels are inadequate.

The anterior choroidal artery (AChA) is an important small branch of the internal carotid artery (ICA). It has an extensive perfusion territory, supplying the posterior two-thirds of the internal capsule, the adjacent optic and auditory radiations, the medial portion of the globus pallidus, the tail of the caudate nucleus, the uncus, the head of the hippocampus, the amygdala, the piriform cortex, and the lateral portion of the lateral geniculate nucleus..$^{11,14,15,39}$ Complete AChA territory infarction thus profoundly impacts a patient's condition, by primarily leading to hemiparesis, hemihypesthesia, and hemianopsia. On the other hand, the AChA does display some anatomical variants and some anastomoses, which explains why not all symptoms are necessarily present. Among the symptoms observed, motor deficits are the most common, sensory deficits more occasional, and hemianopsia and other cortical signs are less frequent. $4,9,15,16,26,29,38,40$ Furthermore, compromised flow through the AChA does not always result in profound neurological deficits. ${ }^{7,31}$

In this study, we performed angiographic and clinical evaluations to assess AChA patency and thus the safety of covering the AChA with an FDS.

ABBREVIATIONS AChA = anterior choroidal artery; FDS = flow-diverter stent; $I C A=$ internal carotid artery; $M C A=$ middle cerebral artery. SUBMITTED July 8, 2014. ACCEPTED November 6, 2014.

INCLUDE WHEN CITING Published online June 5, 2015; DOI: 10.3171/2014.11.JNS141603.

DISCLOSURE Dr. Moret reports consultant relationships with Covidien and MicroVention. 


\section{Methods}

\section{Population and Anatomical Classification}

Between April 2011 and July 2013, 92 FDSs were used in our institution to treat intracranial aneurysms. Of these, $20(21.7 \%)$ covered the AChA, and the corresponding patients were retrospectively included in this study. AChAs feeding the choroid plexus (Fig. 1 left) were classified into a long-course group and those not feeding the choroid plexus (Fig. 1 right) into a short-course group, with few possible anastomoses.

\section{Endovascular Treatment}

All treatments were performed under general anesthesia. Four commercially available FDSs were employed: Silk (Balt), Pipeline (eV3), Fred (MicroVention), and Surpass (Stryker). Aneurysms were treated by 1 of 4 therapeutic approaches: FDS only, both FDS and coils, FDS associated to another non-FDS stent, or FDS with Onyx (eV3). For each case, the selection of the specific FDS and eventual adjunctive therapy depended on the operators' judgment. Patient informed consent was obtained before treatment in each case.

All patients received dual antiplatelet therapy (aspirin $160 \mathrm{mg}$ daily and clopidogrel $75 \mathrm{mg}$ daily) for 7 days before the procedure. The effectiveness of the antiplatelet therapy was tested by light transmission aggregometry and the VerifyNow Aspirin or P2Y12 assays (Accumetrics). All patients responded to the antiplatelet medications. For their postprocedural medication regimen, clopidogrel was maintained for 3 months, and aspirin was continued for 1 year.

All procedures were performed under heparin anticoagulation: $50-\mathrm{U} / \mathrm{kg}$ heparin bolus at the beginning of the procedure, followed by a continuous intravenous infusion of $35-50 \mathrm{U} / \mathrm{kg} / \mathrm{hr}$ to maintain an activated clotting time of 2-2.5 times the baseline.

\section{Procedural Assessment and Follow-Up}

Patency and eventual flow changes in the AChA were checked angiographically immediately after FDS placement and during follow-up. Standard digital subtraction angiography and VasoCT (Philips Healthcare) studies were used to assess AChA patency and any eventual neointimal hyperplasia. In-stent stenosis with neointimal hyperplasia was graded as none $(0 \%)$, mild $(0 \%-25 \%)$, or severe $(>25 \%)$. Postprocedural cone-beam CT was performed systematically to rule out ischemic or hemorrhagic complications. Two of the authors retrospectively and independently of the operators evaluated all angiographic studies.

Neurological exams were performed to evaluate potential ischemic complication in the AChA territory and to rule out hemiparesis, hemihypesthesia, hemianopsia, and other cortical signs. Modified Rankin Scale scores were collected by a neurologist during the preoperative visit and again at each follow-up examination. Symptomatic evolution was retrospectively evaluated from the patients' hospital notes. For the patients who declined a visit to hospital, symptom assessment was made during telephone interviews.

\section{Results}

The results of this study are detailed in Table 1. The included patients were 6 men and 14 women, with a mean age of 58.3 years (range 22-74 years). Silk stents were used in 14 cases, Pipeline stents in 4, and Fred and Surpass stents in 1 case each. Six aneurysms were treated with FDS combined with coils, another stent, or Onyx. The AChA was always covered by a single FDS without other FDS or embolization material. The long-course group included 14 cases and the short-course group 6 cases. Aneurysms were located on the right and left sides in 9 and 11 cases, respectively. Nine aneurysms had a paraclinoid

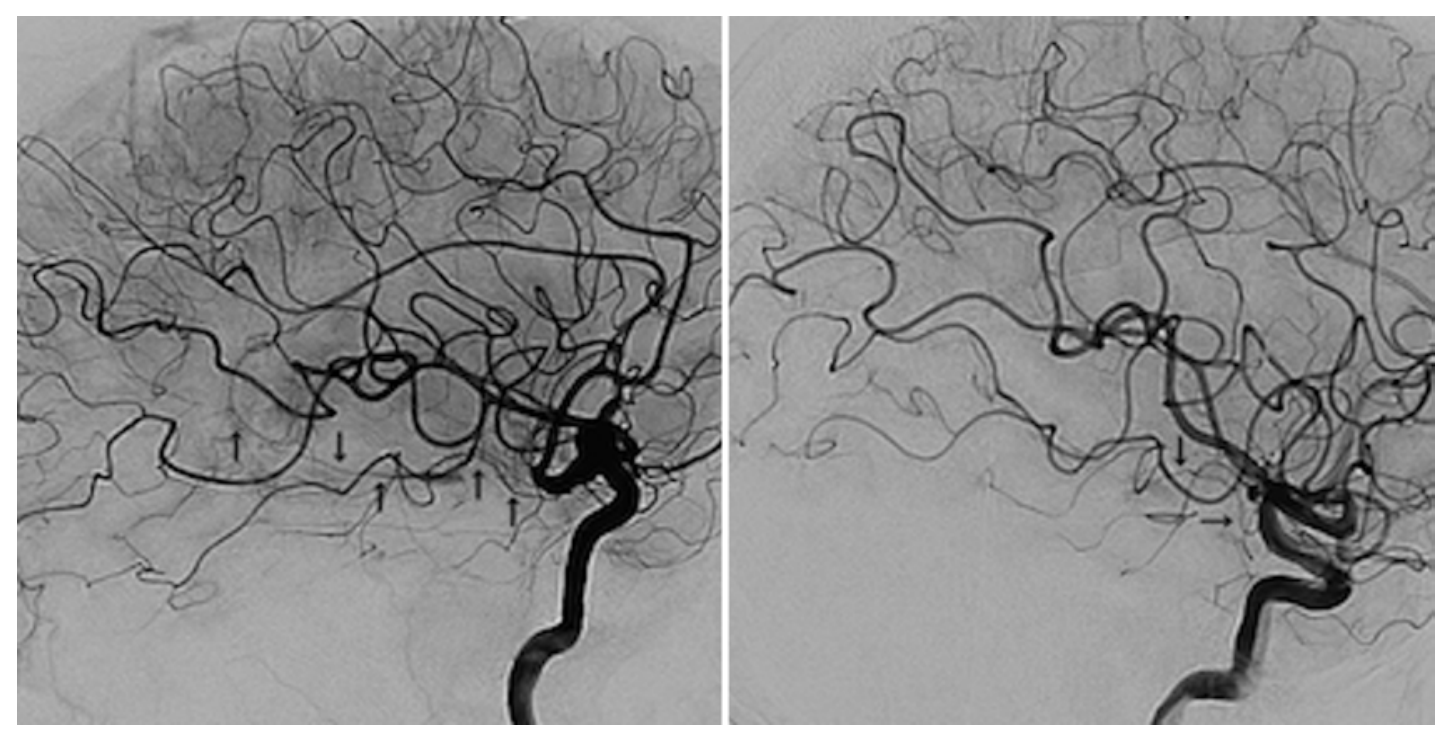

FIG. 1. Representative angiograms illustrating the AChA classification system used in this study. AChAs feeding the choroid plexus (left) were classified into a long-course group and those not feeding the choroid plexus (right) into a short-course group, with few possible anastomoses. The AChAs are indicated by arrows in both images. 
TABLE 1. Summary of treatment and follow-up results for 20 patients with AChA covered with FDS

\begin{tabular}{|c|c|c|c|c|c|c|c|}
\hline $\begin{array}{l}\text { Patient } \\
\text { No. }\end{array}$ & $\begin{array}{l}\text { Age } \\
\text { (yrs) }\end{array}$ & $\begin{array}{l}\text { AChA } \\
\text { Type }\end{array}$ & FDS & $\begin{array}{c}\text { Symptoms w/ AChA Occlusion } \\
\text { on Follow-Up }\end{array}$ & Last Angiography & $\begin{array}{l}\text { AChA Patency on } \\
\text { Last Angiography }\end{array}$ & $\begin{array}{l}\text { Neointimal } \\
\text { Hyperplasia }\end{array}$ \\
\hline 1 & 56 & Short & Silk & No & $2 \mathrm{yrs}$ & Yes & None \\
\hline 2 & 69 & Short & Silk & No & $6 \mathrm{mos}$ & Yes & Mild \\
\hline 3 & 59 & Long & Silk & No & $1 \mathrm{yr}$ & Yes & Mild \\
\hline 4 & 74 & Long & Silk & No & - & - & - \\
\hline 5 & 68 & Long & Silk & No & $1.5 \mathrm{yrs}$ & Yes & None \\
\hline 6 & 67 & Long & Silk & No & $1 \mathrm{yr}$ & Yes & None \\
\hline 7 & 62 & Long & Silk & No & $6 \mathrm{mos}$ & Yes & None \\
\hline 8 & 63 & Long & Silk & No & - & - & - \\
\hline 9 & 22 & Long & Pipeline & No & - & - & - \\
\hline 10 & 30 & Long & Pipeline & No & $1.5 \mathrm{yrs}$ & Yes & None \\
\hline 11 & 46 & Long & Silk & No & $1 \mathrm{yr}$ & Yes & Mild \\
\hline 12 & 74 & Long & Silk & No & $6 \mathrm{mos}$ & Yes & None \\
\hline 13 & 65 & Long & Fred & No & $1 \mathrm{yr}$ & Yes & None \\
\hline 14 & 48 & Short & Silk & No & $6 \mathrm{mos}$ & Yes & None \\
\hline 15 & 65 & Short & Pipeline & No & $6 \mathrm{mos}$ & Yes & Mild \\
\hline 16 & 71 & Long & Silk & No & $6 \mathrm{mos}$ & Yes & None \\
\hline 17 & 56 & Short & Surpass & No & $6 \mathrm{mos}$ & Yes & None \\
\hline 18 & 52 & Short & Silk & No & $6 \mathrm{mos}$ & Yes & None \\
\hline 19 & 64 & Long & Silk & No & $6 \mathrm{mos}$ & Yes & Mild \\
\hline 20 & 55 & Long & Pipeline & No & $6 \mathrm{mos}$ & Yes & Mild \\
\hline
\end{tabular}

location, 4 arose in the posterior communicating artery, 4 in the internal carotid artery bifurcation, 1 in the AChA, 1 in the cavernous part of the ICA, and 1 in the middle cerebral artery. Two patients were undergoing retreatment because of recanalization after coiling. We noted no angiographic AChA flow changes immediately after FDS placement, and no ischemic changes in the AChA territory on the postprocedural CT scan. The angiographic data obtained for 17 patients $(85.0 \%)$ over a mean follow-up duration of $9.8 \pm 5.4$ months confirmed the maintenance of AChA patency in all cases (Fig. 2), with no change in AChA flow. Six patients (35.3\%) presented mild neointimal hyperplasia.

No patients were lost to clinical follow-up (mean duration $9.6 \pm 6.3$ months). Two patients exhibited contralateral paresis before FDS treatment, one due to cerebral vasospasm and the other to intracerebral hemorrhage; neither of these patients showed any deterioration in their condition after FDS treatment. One patient had third cranial nerve palsy due to a posterior communicating artery aneurysm. No patient in either group complained of transient or permanent symptoms suggestive of AChA thromboembolic complication.

\section{Discussion}

Considering the increased risk of thrombotic complications with impaired flow in the AChA, ${ }^{20,21}$ every effort should be made to preserve the patency of the AChA during endovascular treatment of intracranial aneurysms. According to results from several large clinical studies evaluating FDS use to treat intracranial aneurysms, $0 \%-11 \%$ of patients experienced acute ischemic com- plications and $0 \%-12 \%$ experienced delayed ischemic complications. $3,5,12,27,28,32,36$ Evidence suggests that most thromboembolic complications after FDS placement occur in the distal branches and parent arteries but not in the small branches, and that the covered branch arteries are safe provided that flow rate is maintained through the FDS. $25,28,36$

While several studies have reported cases of FDScovered AChAs remaining patent on angiographic assessment, no clear explanation of this observation yet exists. ${ }^{8,22,34,37}$ Some new FDS models have a low-porosity design on both ends, a specificity that, according to some authors, ${ }^{22}$ could help maintain anterograde flow in small covered vessels such as the AChA during the treatment of carotid siphon aneurysms. Considering the lack of any clear explanation for the observed safety of covering small side-wall branch arteries such as the AChA with an FDS, we tried whenever possible to avoid covering the AChA with the FDS. However in 1 of 5 cases, covering the AChA was unavoidable.

In those cases where the AChA was covered, we observed no acute or delayed thromboembolic events. All AChAs remained patent without stenosis, as observed by angiography, and no patient displayed any related neurological deficit. This would suggest, therefore, that the AChA can be safely covered with a single FDS regardless of anatomy and potential for anastomosis. What remains uncertain is whether the factors that prevent occlusion of the AChA depend on 1) its anatomical location, 2) the possibility of collateral supply, 3 ) its diameter in comparison with the size of the FDS struts, or 4) the difference between its diameter and that of the ICA. 

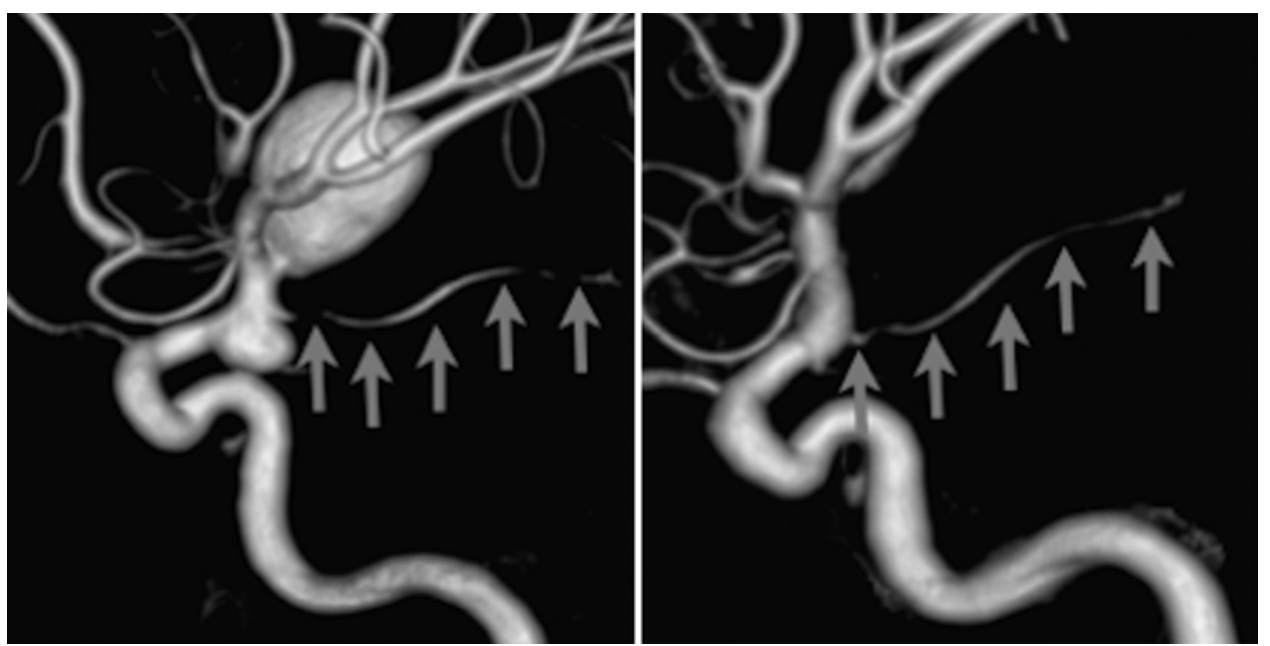

FIG. 2. 3D rotational digital subtraction angiograms obtained before (left) and 6 months after (right) FDS treatment of 2 intracranial aneurysms. The follow-up angiogram shows that the aneurysms are excluded and the covered AChA remains patent without stenosis. The AChA is indicated by arrows in both images.

In a study involving rabbits, the branch arteries covered with an FDS fitted in the descending aorta remained patent. ${ }^{18}$ However, some covered branches may still occlude after FDS placement, even with appropriate antiplatelet premedication and testing. In humans, Lall et al. ${ }^{24}$ recently reported the acute occlusion of 3 major arteries covered with an FDS (posterior cerebral artery, posterior inferior cerebellar artery, and a branch of the middle cerebral artery [MCA]). Another study involving 25 cases of MCA aneurysm treated with FDS reported reduced filling in 6 branches and asymptomatic occlusion in 3 at follow-up. ${ }^{42}$ In the hands of Pistocchi et al., ${ }^{33}$ only $38.1 \%$ of arterial branches beyond the level of the circle of Willis that were covered with an FDS remained patent, with asymptomatic occlusion in $38.1 \%$ of them and slow flow modifications in the remaining $23.8 \%$. In their studies, almost all of the covered branches described as being occluded or having a reduced flow were in fact bifurcation branches rather than small side branches.

A few reports have focused on the FDS covering another small side-wall branch vessel, the ophthalmic artery. Szikora et al. ${ }^{37}$ reported 1 acute and 2 delayed ophthalmic artery occlusions in 19 cases of ICA aneurysms treated with FDS. In their detailed study, Puffer et al. ${ }^{34}$ reported an immediate change in flow in $15 \%$ of ophthalmic arteries covered with FDSs, and delayed occlusion observed on follow-up angiograms in approximately $25 \%$. In another recent FDS study, 2 of 15 cases of covered ophthalmic arteries lost their anterograde flow without any clinical consequence. ${ }^{8}$ No AChA occlusion was described in these studies.

Puffer et al. ${ }^{34}$ stated that the ophthalmic artery is like the AChA in that it is a small branch arising from the ICA, yet it differs from the AChA in terms of anastomosis, especially with external carotid arteries. Indeed, should ophthalmic artery inflow be reduced by an FDS, the distal bed takes over the supply from other anastomotic external carotid artery branches. However, the AChA also has some anastomoses with other small branches. ${ }^{6,13,17}$ After the AChA's ventricular penetration, branches to cerebral tis- sue are absent, and it connects with some choroidal anastomoses. ${ }^{41}$ The extent and location of lesions produced by occlusions of the AChA vary, owing to anastomosis of the AChA with the posterior choroidal artery, interpeduncular plexus, and posterior communicating artery. ${ }^{6,35}$ In our study, 14 cases were classified into the long-course group and were expected to have effective anastomoses with other choroidal branches. Nevertheless, no patient in either group presented with symptoms relating to AChA occlusion. These results suggest that the patency of the AChA covered with an FDS may be maintained irrespective of the anatomy and potential collateral flow.

In addition, it should be noted that in the series reported by Puffer et al., the average number of FDSs was 2.1 per aneurysm, suggesting a possible increase in risk of AChA occlusion in cases of multiple FDS coverage.

While the AChA is a smaller artery than bifurcation branches, it is still larger than the FDS pore size. ${ }^{12,23,35}$ One in vitro study ${ }^{2}$ showed that the open space area of the Silk stent varies from 0.01 to $0.084 \mathrm{~mm}^{2}$ while the area of the origin of the AChA can vary from 0.4 to $1.1 \mathrm{~mm}^{2}$ (mean $\left.0.9 \mathrm{~mm}^{2}\right) .{ }^{35}$ Kallmes et al. ${ }^{18}$ suggested that provided a rapid flow remained in an artery across the FDS struts, the tendency for occlusion would be almost absent. In acute and follow-up angiography, no slow flow phenomenon was evident in any of the cases, including our cases. Thus, the maintenance of AChA patency may be due to the much smaller diameter of this vessel in comparison with the parent artery, resulting in rapid flow through the stent struts. Indeed, in general, the diameter of the feeding artery might impact the small branch artery occlusion rate.

We observed neointimal hyperplasia in $35.3 \%$ of cases in the present study. The impact on thromboembolic events of neointimal hyperplasia, considered a normal response to FDS, ${ }^{30}$ is difficult to assess. In animal models, consistently more neointimal hyperplasia occurred at the level of the aneurysm than in the branch vessel..$^{19}$ In the present study, no neointimal hyperplasia was observed at the AChA entrance.

Our study has several limitations. First, it was retro- 
spective and included a relatively small number of patients. We also used different types of FDS, although the Silk and Pipeline are braided with the same number of wires and would therefore be expected to have similar porosity. ${ }^{12,13}$ As angiographic follow-up was only available in $85 \%$ of cases, we were unable to exclude the occurrence of some asymptomatic AChA occlusions. Furthermore, our clinical follow-up data only included symptomatic evaluations; the patients were not evaluated by detailed MRI. The longest angiographic follow-up data were acquired 1.5 years after treatment; longer follow-up is now needed to evaluate long-term AChA patency.

\section{Conclusions}

The results of this study suggest that, when impossible to avoid, the AChA may be safely covered with a single FDS placed to treat an intracranial aneurysm, irrespective of the anatomy and anastomoses.

\section{Acknowledgment}

We would like to express our greatest appreciation to Prof. S. Ishihara (Saitama Medical University International Medical Center, Department of Endovascular Neurosurgery, Saitama, Japan) who offered continuing interest and constant encouragement.

\section{References}

1. Berge J, Biondi A, Machi P, Brunel H, Pierot L, Gabrillargues J, et al: Flow-diverter silk stent for the treatment of intracranial aneurysms: 1-year follow-up in a multicenter study. AJNR Am J Neuroradiol 33:1150-1155, 2012

2. Blackshear WM, Phillips DJ, Chikos PM, Harley JD, Thiele BL, Strandness DE Jr: Carotid artery velocity patterns in normal and stenotic vessels. Stroke 11:67-71, 1980

3. Briganti F, Napoli M, Tortora F, Solari D, Bergui M, Boccardi E, et al: Italian multicenter experience with flow-diverter devices for intracranial unruptured aneurysm treatment with periprocedural complications - a retrospective data analysis. Neuroradiology 54:1145-1152, 2012

4. Bruno A, Graff-Radford NR, Biller J, Adams HP Jr: Anterior choroidal artery territory infarction: a small vessel disease. Stroke 20:616-619, 1989

5. Byrne JV, Beltechi R, Yarnold JA, Birks J, Kamran M: Early experience in the treatment of intra-cranial aneurysms by endovascular flow diversion: a multicentre prospective study. PLoS ONE 5:e12942, 2010

6. Carpenter MB, Noback CR, Moss ML: The anterior choroidal artery; its origins course, distribution, and variations. AMA Arch Neurol Psychiatry 71:714-722, 1954

7. Das K, Benzil DL, Rovit RL, Murali R, Couldwell WT: Irving S. Cooper (1922-1985): a pioneer in functional neurosurgery. J Neurosurg 89:865-873, 1998

8. De Vries J, Boogaarts J, Van Norden A, Wakhloo AK: New generation of flow diverter (Surpass) for unruptured intracranial aneurysms: a prospective single-center study in 37 patients. Stroke 44:1567-1577, 2013

9. Decroix JP, Graveleau P, Masson M, Cambier J: Infarction in the territory of the anterior choroidal artery. A clinical and computerized tomographic study of 16 cases. Brain 109:1071-1085, 1986

10. D'Urso PI, Lanzino G, Cloft HJ, Kallmes DF: Flow diversion for intracranial aneurysms: a review. Stroke 42:2363-2368, 2011

11. Feekes JA, Hsu SW, Chaloupka JC, Cassell MD: Tertiary microvascular territories define lacunar infarcts in the basal ganglia. Ann Neurol 58:18-30, 2005
12. Fischer S, Vajda Z, Aguilar Perez M, Schmid E, Hopf N, Bäzner H, et al: Pipeline embolization device (PED) for neurovascular reconstruction: initial experience in the treatment of 101 intracranial aneurysms and dissections. Neuroradiology 54:369-382, 2012

13. Galatius-Jensen F, Ringberg V: Anastomosis between the anterior choroidal artery and the posterior cerebral artery demonstrated by arteriography. Radiology 81:942-944, 1963

14. Ghika JA, Bogousslavsky J, Regli F: Deep perforators from the carotid system. Template of the vascular territories. Arch Neurol 47:1097-1100, 1990

15. Hamoir XL, Grandin CB, Peeters A, Robert A, Cosnard G, Duprez T: MRI of hyperacute stroke in the AChA territory. Eur Radiol 14:417-424, 2004

16. Hupperts RM, Lodder J, Heuts-van Raak EP, Kessels F: Infarcts in the anterior choroidal artery territory. Anatomical distribution, clinical syndromes, presumed pathogenesis and early outcome. Brain 117:825-834, 1994

17. Hussein S, Renella RR, Dietz H: Microsurgical anatomy of the anterior choroidal artery. Acta Neurochir (Wien) 92:1928,1988

18. Kallmes DF, Ding YH, Dai D, Kadirvel R, Lewis DA, Cloft HJ: A new endoluminal, flow-disrupting device for treatment of saccular aneurysms. Stroke 38:2346-2352, 2007

19. Kallmes DF, Ding YH, Dai D, Kadirvel R, Lewis DA, Cloft HJ: A second-generation, endoluminal, flow-disrupting device for treatment of saccular aneurysms. AJNR Am J Neuroradiol 30:1153-1158, 2009

20. Kang HS, Kwon BJ, Kwon OK, Jung C, Kim JE, Oh CW, et al: Endovascular coil embolization of anterior choroidal artery aneurysms. Clinical article. J Neurosurg 111:963-969, 2009

21. Kim BM, Kim DI, Chung EC, Kim SY, Shin YS, Park SI, et al: Endovascular coil embolization for anterior choroidal artery aneurysms. Neuroradiology 50:251-257, 2008

22. Kocer N, Islak C, Kizilkilic O, Kocak B, Saglam M, Tureci $\mathrm{E}$ : Flow re-direction endoluminal device in treatment of cerebral aneurysms: initial experience with short-term followup results. J Neurosurg 120:1158-1171, 2014

23. Kulcsár Z, Ernemann U, Wetzel SG, Bock A, Goericke S, Panagiotopoulos V, et al: High-profile flow diverter (silk) implantation in the basilar artery: efficacy in the treatment of aneurysms and the role of the perforators. Stroke 41:16901696,2010

24. Lall RR, Crobeddu E, Lanzino G, Cloft HJ, Kallmes DF: Acute branch occlusion after Pipeline embolization of intracranial aneurysms. J Clin Neurosci 21:668-672, 2014

25. Lanzino G, Crobeddu E, Cloft HJ, Hanel R, Kallmes DF: Efficacy and safety of flow diversion for paraclinoid aneurysms: a matched-pair analysis compared with standard endovascular approaches. AJNR Am J Neuroradiol 33:21582161,2012

26. Leys D, Mounier-Vehier F, Lavenu I, Rondepierre P, Pruvo JP: Anterior choroidal artery territory infarcts. Study of presumed mechanisms. Stroke 25:837-842, 1994

27. Lubicz B, Collignon L, Raphaeli G, Pruvo JP, Bruneau M, De Witte O, et al: Flow-diverter stent for the endovascular treatment of intracranial aneurysms: a prospective study in 29 patients with 34 aneurysms. Stroke 41:2247-2253, 2010

28. Lylyk P, Miranda C, Ceratto R, Ferrario A, Scrivano E, Luna $\mathrm{HR}$, et al: Curative endovascular reconstruction of cerebral aneurysms with the pipeline embolization device: the Buenos Aires experience. Neurosurgery 64:632-643, quiz N6, 2009

29. Mohr JP, Steinke W, Timsit SG, Sacco RL, Tatemichi TK: The anterior choroidal artery does not supply the corona radiata and lateral ventricular wall. Stroke 22:1502-1507, 1991

30. Nelson PK, Lylyk P, Szikora I, Wetzel SG, Wanke I, Fiorella D: The Pipeline embolization device for the intracranial treatment of aneurysms trial. AJNR Am J Neuroradiol 32:34-40, 2011 
31. Perria L, Viale GL, Rivano C: Further remarks on the surgical treatment of carotid-choroidal aneurysms. Acta Neurochir (Wien) 24:253-262, 1971

32. Piano M, Valvassori L, Quilici L, Pero G, Boccardi E: Midterm and long-term follow-up of cerebral aneurysms treated with flow diverter devices: a single-center experience. J Neurosurg 118:408-416, 2013

33. Pistocchi S, Blanc R, Bartolini B, Piotin M: Flow diverters at and beyond the level of the circle of Willis for the treatment of intracranial aneurysms. Stroke 43:1032-1038, 2012

34. Puffer RC, Kallmes DF, Cloft HJ, Lanzino G: Patency of the ophthalmic artery after flow diversion treatment of paraclinoid aneurysms. J Neurosurg 116:892-896, 2012

35. Rhoton AL Jr, Fujii K, Fradd B: Microsurgical anatomy of the anterior choroidal artery. Surg Neurol 12:171-187, 1979

36. Saatci I, Yavuz K, Ozer C, Geyik S, Cekirge HS: Treatment of intracranial aneurysms using the Pipeline flow-diverter embolization device: a single-center experience with longterm follow-up results. AJNR Am J Neuroradiol 33:14361446,2012

37. Szikora I, Berentei Z, Kulcsar Z, Marosfoi M, Vajda ZS, Lee $\mathrm{W}$, et al: Treatment of intracranial aneurysms by functional reconstruction of the parent artery: the Budapest experience with the Pipeline embolization device. AJNR Am J Neuroradiol 31:1139-1147, 2010

38. Takahashi S, Ishii K, Matsumoto K, Higano S, Ishibashi T, Suzuki M, et al: The anterior choroidal artery syndrome. II. $\mathrm{CT}$ and/or MR in angiographically verified cases. Neuroradiology 36:340-345, 1994

39. Tatu L, Moulin T, Bogousslavsky J, Duvernoy H: Arterial territories of the human brain: cerebral hemispheres. Neurology 50:1699-1708, 1998

40. Tei H, Uchiyama S, Maruyama S: Capsular infarcts: location, size and etiology of pure motor hemiparesis, sensorimotor stroke and ataxic hemiparesis. Acta Neurol Scand 88:264268, 1993

41. Théron J, Newton TH: [Anterior choroidal artery. I. Anatomic and radiographic study.] J Neuroradiol 3:5-30, 1976 (Fr)

42. Yavuz K, Geyik S, Saatci I, Cekirge HS: Endovascular treatment of middle cerebral artery aneurysms with flow modification with the use of the Pipeline embolization device. AJNR Am J Neuroradiol 35:539-535, 2013

\section{Author Contributions}

Conception and design: Neki, Caroff, Spelle. Acquisition of data: Neki. Analysis and interpretation of data: Neki, Caroff, Spelle. Drafting the article: Neki, Caroff, Jittapiromsak, Benachour, Mihalea, Ikka. Critically revising the article: Neki, Caroff, Spelle. Reviewed submitted version of manuscript: all authors. Approved the final version of the manuscript on behalf of all authors: Neki. Statistical analysis: Neki, Caroff. Administrative/technical/ material support: Neki, Spelle. Study supervision: Neki, Caroff, Moret, Spelle.

\section{Correspondence}

Hiroaki Neki, Interventional Neuroradiology NEURI Center, Beaujon Hospital, Paris Diderot University, 100 Boulevard du General Leclerc, Clichy 92118, France. email: nekihiro1004@ gmail.com. 